\title{
EDUKASI PENGHIJAUAN MENUJU DESA ASRI PADA MASYARAKAT DESA WAESUHAN
}

\author{
Samsia Umasugi ${ }^{1}$, Samsul Bahari², Muh. Iksan ${ }^{3}$, Azaluddin $^{2}$, Eriyawan Buton ${ }^{1}$, Susiati** \\ ${ }^{1}$ Budidaya Perairan/FAPERIK Universitas Iqra Buru \\ ${ }^{2}$ Akuntansi/Fakultas Ekonomi Universitas Muhammadiyah Buton \\ ${ }^{3}$ Pendidikan Biologi/FKIP Universitas Muhammadiyah Buton \\ ${ }^{4}$ Sastra Indonesia/Fakultas Sastra Universitas Iqra Buru \\ ${ }^{*}$ Coresponding-Author : samsiaumasugi@gmail.com
}

\begin{abstract}
ABSTRAK. Tujuan kegiatan Pengabdian Kepada Masyarakat ini adalah untuk memberikan edukasi penghijauan menuju Desa ASRI (Aman, Sehat, Rindang, Indah) kepada masyarakat Dusun Waesuhan. Masalah yang dihadapi oleh mitra, yakni terdapat banyak lahan tandus yang tidak ditanami pepohonan, kurangnya pengetahuan masyarakat terhadap pentingnya penghijauan dan pengelolaan lingkungan. Untuk itu, pengusul bersama mitra sasaran PKM akan menawarkan solusi, yakni menggiatkan edukasi penghijauan menuju Desa ASRI (Aman, Sehat, Rindang, Indah) kepada masyarakat Dusun Waesuhan, Desa Wanakarta, Kecamatan Lolongguba, Kabupaten Buru. Solusi ini dianggap penting untuk meningkatkan kepedulian masyarakat terhadap lingkungan sekitar mereka. Pendekatan yang digunakan dalam kegiatan pengabdian ini adalah pendekatan PAR (Participatory Action Research), yakni berupa edukasi berbasis teori dan praktik. Hasil kegiatan menunjukkan bahwa Edukasi berbasis teori menekankan kepada dua materi inti, yaitu materi Pengelolaan Lingkungan Hidup dan materi Penghijauan. Sementara, edukasi berbasis praktik, yakni melakukan penanaman pohon sebanyak 100 bibit pohon. Hasil dari penerapan edukasi tersebut kepedulian masyarakat pada lingkungan semakin tinggi, hal tersebut ditandai dengan antusiasnya masyarakat Dusun Waesuhan mengikuti jalannya PKM ini.
\end{abstract}

Kata Kunci: edukasi, penghijauan, ASRI

ABSTRACT. The purpose of this Community Service activity is to provide greening education towards ASRI Village (Safe, Healthy, Shady, Beautiful) to the people of Waesuhan Hamlet. The problems faced by partners are that there are many barren lands that are not planted with trees, the lack of community knowledge about the importance of reforestation and environmental management. For this reason, the proposer and the PKM target partners will offer a solution, namely to promote greening education towards ASRI Villages (Safe, Healthy, Shady, Beautiful) to the people of Waesuhan Hamlet, Wanakarta Village, Lolongguba District, Buru Regency. This solution is considered important to increase public awareness of the environment around them. The approach used in this service activity is the PAR (Participatory Action Research) approach, which is in the form of theory and practice-based education. The results of the activity show that theory-based education emphasizes two core materials, namely Environmental Management material and Greening material. Meanwhile, practice-based education, namely planting 100 tree seedlings. The result of the implementation of this education is that the public's concern for the environment is getting higher, this is indicated by the enthusiasm of the people of Dusun Waesuhan following the PKM.

Keyword: education, greening, ASRI

\section{PENDAHULUAN}

Dusun Waessuhan merupakan salah satu Dusun yang ada di Desa Wanakarta, Kecamatan Lolongguba, Kabupaten Buru. Kondisi sosial masyarakat di Desa Wanakarta dominan pedagang dan Petani. 
Lingkungan yang sehat merupakan impian dan harapan bagi setiap individu. Namun, untuk mewujudkan keadaan itu perlu dengan berbagai pendekatan, baik melalui sosialisasi ataupun edukasi karena di tengah-tengah lingkungan masyarakat masih banyak temuan terkait kurangnya warga yang peduli dan menggiatkan kepedulian terhadap lingkungan sekitar mereka. Selain itu, warga pun masih banyak yang tidak bertanggung jawab terhadap kepedulian lingkungan misalnya menebang pohon secara liar dengan tidak menggantinya dengan menanam pohon baru. Sikap hidup tersebut sangatlah mengkhawatirkan dan untuk membangun kesadaran masyarakat terhadap kepedulian lingkungan tidaklah mudah, memerlukan sebuah proses yang panjang misalnya harus melalui proses kerjasama yang tinggi, saling membangun kepercayaan, menumbuhkan komitmen bersama. Di Dusun Wesuhan sendiri banyak lahan-lahan kosong akibat terjadinya penebangan pohon baik itu pohon-pohon berukuran kecil maupun berukuran besar. Masyarakat pun masih kurang memiliki kepedulian terhadap lingkungan. Hal tersebut dikarenakan kurangnya mendapatkan edukasi-edukasi terkait pengelolaan lingkungan dan penumbuhan sikap cinta lingkungan.

Pasal 1 ayat 1 Undang-Undang Nomor 32 Tahun 2009 tentang pengelolaan Lingkungan Hidup adalah kesatuan ruang dengan semua benda, daya, keadaan, dan makhluk hidup termasuk manusia dan perilakunya yang mempengaruhi alam itu sendiri, kelangsungan perikehidupan dan kesejahteraan umum serta makhluk hidup lain (Adhistian et al., 2021). Penghijauan merupakan salah satu bentuk peran manusia dalam menjaga lingkungan. Penghijauan ini dilakukan dengan melakukan penanaman pepohonan. Tujuan penghijauan sendiri adalah untuk mendukung lingkungan agar terlihat ASRI (Aman, Sehat, Rindang, Indah). Selain memberikan kesan ASRI, penghijauan ini juga memberikan banyak manfaat bagi lingkungan. Pohon-pohon yang ditanam akan mengatasi polusi yang banyak dihasilkan di jalan raya, dan memberikan suplai oksigen bagi manusia. Salah satu manfaat penghijauan ialah untuk mencegah erosi tanah. Erosi tanah adalah masalah yang umum yang sering terjadi di tanah yang tandus. Tanah yang tandus akan mengalami angin kencang yang membawa partikel-partikel besar dari tanah sehingga menyebabkan erosi tanah dan juga berdampak negatif pada kualitas udara (Harryanto et al., 2017).

Ada beberapa kegiatan PKM terdahulu yang mejadi rujukan PKM ini, yakni Diah Ayu Pratiwi (2017) melakukan PKM dengan judul Pemberdayaan Masyarakat RW 12 dalam Kegiatan Penghijauan Lingkungan di Kavling Mandiri Kelurahan Sei Pelunggut. Hasil yang diperoleh dari PKM ini adalah bahwa melalui pendekatan persuasif dapat meningkatkan peran serta masyarakat RW 12 dalam kegiatan penghijauan lingkungan. Terlihat dari tingginya partisipasi masyarakat mulai dari kalangan tua sampai kalangan muda ikut dalam kegiatan penanaman pohon dan gotong royong. Kegiatan penghijauan lingkungan melalui penanaman pohon dapat meningkatkan kualitas lingkungan di RW 12 dan meningkatkan daya serap air guna mencegah terjadinya banjir, serta membuat lingkungan RW 12 menjadi asri dan rindang. Masyarakat dapat berperilaku bersih dengan tidak membuang sampah sembarangan, sehingga lingkungan menjadi rapi dan bersih (Pratiwi, 2017).

Hery Setyobudiarso et. al (2020) melakukan PKM dengan judul Kegiatan Penghijauan di Pesisir Watu Later Dusun Rawatrate, Desa Sitiarjo, Kabupaten Malang. Hasil yang diperoleh dari PKM ini adalah para tim melakukan beberapa kegiatan, yakni kegiatan bersih-bersih di areal pesisir Watu Leter yang akan dijadikan lokasi penghijauan, kegiatan penanaman bibit pohon buah, dan kegiatan pemeliharaan tanaman buah dalam upaya konservasi lingkungan yang merupakan tanggung jawab bersama dilakukan secara bergiliran dengan sistem piket harian (Setyobudiarso et al., 2020).

Nurul Imamah (2021) melakukan PKM dengan judul Gerakan Penghijauan sebagai Rintisan Desa Wisata untuk Meningkatkan Income Masyarakat di Desa Sumokali, Candi, Sidoarjo. Hasil yang diperoleh dari PKM ini adalah pelaksanaan penanaman 100 pucuk merah. Selanjutnya, 
keberhasilan program desa wisata dapat meningkatkan pendapatan dan membantu meningkatkan kualitas lingkungan di Desa Sumokali sehingga tercipta masyarakat yang sehat sebagai pendukung program desa wisata dan peningkatan pendapatan masyarakat melalui UMKM (Imamah, 2021).

Para tim pengabdi akan melakukan kegiatan PKM terkait edukasi penghijauan di Desa Waesuhan dengan tujuan agar para warga dapat memperoleh berbagai ilmu pengetahuan dan informasi tentang pentingnya menjaga lingkungan sekitar dari berbagai bencana salah satunya melalui penghijauan. Untuk mencapai kelestarian lingkungan, manusia mulai menyadari perlunya penghijauan untuk mencegah terjadinya masalah lingkungan di masa depan sehingga dibutuhkan upaya nyata untuk meningkatkan kualitas lingkungan, salah satunya adalah dengan menumbuhkan sikap peduli lingkungan melalui edukasi penghijauan kepada masyarakat (Wardani \& Putra, 2020).

Tujuan dari kegiatan PKM ini adalah untuk memberikan edukasi penghijauan menuju Desa ASRI (Aman, Sehat, Rindang, Indah) kepada masyarakat Desa Waesuhan Kabupaten Buru.

\section{ANALISIS PERMASALAHAN}

Melalui observasi langsung ke Dusun Waesuhan tampak beberapa masalah yang dihadapi oleh mitra, yakni terdapat banyak lahan tandus yang tidak ditanami pepohonan, kurangnya pengetahuan masyarakat terhadap pentingnya penghijauan dan pengelolaan lingkungan. Di tambah lagi dengan pencemaran udara meningkat. Jalanan dipenuhi dengan asap kendaraan bermotor sehingga kadar karbon dioksida menjadi sangat tinggi, udara semakin panas, serta kondisi lingkungan hidup yang kurang baik. Manusia bernafas mengeluarkan kadar karbon dioksida yang bisa membuat suhu semakin panas dan jika tidak ada pohon yang mengubah karbon dioksida tersebut maka oksigen menjadi terbatas.

\section{SOLUSI YANG DITAWARKAN}

Bertolak dari permasalahan yang diperoleh melalui observasi langsung, maka pengusul bersama mitra sasaran PKM akan menggiatkan Edukasi Penghijauan kepada Masyarakat Dusun Waesuhan, Desa Wanakarta.

Solusi terkait Edukasi Penghijauan menuju Desa ASRI kepada Masyarakat Dusun Waesuhan, Desa Wanakarta akan diimplementasikan dalam bentuk edukasi berbasis teori dan praktik. Adapun edukasi berbasis teori memuat materi Pengelolaan Lingkungan Hidup dan materi Penghijauan. Sementara, edukasi berbasis praktik memuat penerapan langsung penanaman pohon di tiap titik lokasi yang telah ditentukan.

Pendekatan yang digunakan dalam kegiatan pengabdian ini adalah pendekatan PAR (Participatory Action Research), yakni berupa edukasi penghijauan berbasis teori dan praktik. Adapun tahapan pelaksanaan Edukasi Penghijauan pada Masyarakat Dusun Waesuhan sebagai berikut 1) tahap persiapan, tahap ini akan dilakukan peninjauan dan pengidentifikasian permasalahan mitra; 2) tahap pelaksanaan, yakni penerapan edukasi berbasis teori dan berbasis praktik terkait penghijauan; 3) tahap evaluasi, yakni akan dilakukan pengawasan dan pengontrolan secara berkala sesuai dengan kesepakatan dari tim pengabdi dan mitra.

\section{HASIL DAN PEMBAHASAN}

Pelaksanaan PKM dilaksanakan selama 2 hari. Hasil dari PKM ini dibagi ke dalam 3 Tahap kegiatan, yakni:

\section{Tahap Persiapan}

Pada tahap ini, yang dilakukan oleh tim pengabdi adalah melakukan koordinasi dengan perangkat Desa Wanakarta untuk mengadakan PKM di Dusun Waesuhan. Setelah tim mendapatkan rekomendasi dari Kepala Desa Wanakarta, kemudian tim berkoordinasi dengan Ketua 
RT Waesuhan. Setelah mendapat izin dari Kepala Desa Wanakarta, tim melakukan observasi lapangan terkait kondisi daerah Dusun Waesuhan dan hasil dari observasi tersebut tim menemukan dan langsung menentukan beberapa permasalahan. Kemudian, tim pengabdi melakukan analisa dari tiap permasalahan yang ditemukan di lapangan. Setelah satu persatu permasalahan selesai dianalisis, tim menentukan metode yang cocok untuk mengatasi masalah tersebut. Terakhir tim membagi tugas masing-masing.

\section{Tahap Pelaksanaan}

Dalam tahap Pelaksanaan ini, tim pengabdi menetapkan metode edukasi terkait penghijauan sebagai cara untuk menyelesaikan masalah yang dihadapi oleh mitra sasaran. Penerapan edukasi penghijauan ini dilakukan dalam dua cara, yakni edukasi penghijauan berbasis teori dan edukasi penghijauan berbasis praktik.

\section{Edukasi Penghijauan Berbasis Teori}

Pelaksanaan edukasi berbasisi teori ini, tim pengabdi mengangkat 2 materi utama, yakni materi Pengelolaan Lingkungan dan materi Penghijauan. Pelaksanaan program ini dihadiri oleh 25 orang yang terdiri dari para perangkat desa dan masyarakat Dusun Waesuhan.

Pada materi Pengelolaan Lingkungan Hidup yang ditekankan oleh tim pengabdi adalah terkait pengertian pengelolaan lingkungan, tujuan dan sasaran pengelolaan lingkungan, dan permasalahan lingkungan hidup. Pemateri pun menekankan bahwa pengelolaan lingkungan hidup adalah upaya terpadu untuk melestarikan fungsi lingkungan hidup yang meliputi kebijaksanaan penataan, pemanfaatan, pengembangan, pemeliharaan, pemulihan, pengawasan, dan pengendalian lingkungan hidup.

Pengelolaan lingkungan hidup bukan hanya menjadi tanggung jawab pemerintah. Masyarakat juga ikut berperan serta dalam melaksanakan kebijaksanaan pengelolaan lingkungan hidup. Setiap orang mempunyai hak dan kewajiban berperan serta dalam pengelolaan lingkungan hidup, sehingga dapat tercapai kelestarian fungsi lingkungan hidup. Pelestarian fungsi lingkungan hidup merupakan sejumlah upaya dalam memelihara kelangsungan daya dukung dan daya tampung lingkungan hidup. Daya dukung merupakan kemampuan lingkungan hidup untuk mendukung perikehidupan manusia dan makhluk hidup lain, sedangkan daya tampung lingkungan hidup adalah kemampuan lingkungan hidup untuk menyerap zat, energi, atau komponen lain yang masuk atau dimasukkan ke dalamnya.

Selain itu, yang perlu diketahui oleh peserta dalam edukasi penghijauan ini adalah sasaran pengelolaan lingkungan hidup adalah tercapainya kelestarian lingkungan hidup, terjaminnya kepentingan generasi masa kini serta generasi masa depan, terwujudnya masyarakat Indonesia sebagai manusia yang mempunyai sikap dan perilaku melindungi lingkungan hidup, tercapainya keserasian, keseimbangan serta keselarasan antarmanusia dan lingkungan hidup, dapat terkendali pemanfaatan sumber daya secara arif dan bijaksana, terlindunginya lingkungan masyarakat dari dampak usaha yang menyebabkan pencemaran atau pengrusakan lingkungan hidup.

Pada materi Penghijauan, yang ditekankan oleh pemateri adalah peranan penghijauan lingkungan dan manfaat penghijauan. Penghijauan adalah salah satu upaya rehabilitasi lahan kritis dan di luar kawasan hutan dengan maksud untuk memulihkan, mempertahankan, dan meningkatkan fungsi lahan sesuai dengan kemampuan, yakni untuk kepentingan fungsi tata air, fungsi produksi, dan fungsi perlindungan.

Tujuan utama penghijauan, yakni untuk mengendalikan banjir dan erosi tanah, meningkatkan kesejahteraan rakyat dan mengubah perilaku petani sebagai pelestari SDA (Sumber Daya Alam). Lahan-lahan kritis yang biasanya mudah terkena erosi dengan kesuburan tanah yang rendah dan 
keterbatasan dalam masalah air, menyebabkan kegiatan penghijauan dan pengembalian kesuburan tanah mutlak diperlukan. Adapun peranan penghijauan terhadap manusia dan lingkungan antara lain:

1) Fungsi Klimatologis, yakni sebagai pengatur iklim mikro,

2) Fungsi Protektif, yakni sebagai perlindungan,

3) Fungsi Higienis, yakni berperan penting dalam kesehatan lingkungan

4) Fungsi Hidrologis, yakni sebagai pengatur persediaan air dalam tanah

5) Fungsi Erologis, berfungsi sebagai pencegah erosi

6) Fungsi Edhapis, yakni sebagai tempat hidup satwa

7) Fungsi Estetis, yakni mempunyai nilai keindahan

8) Fungsi Psikis, yakni terkait dengan kejiwaan

9) Fungsi Edukatif, yakni memberikan pendidikan,

10) Fungsi Ekologi, yakni mempertinggi kualitas ruang kehidupan lingkungan

11) Fungsi Sosial Ekonomi.

Hasil yang diperoleh dari selesainya edukasi penghijauan berbasis teori ini bahwa peserta mendapat berbagai ilmu pengetahuan dan informasi terkait pengelolaan lingkungan hidup dan penghijauan. Saat diskusi peserta banyak mengajukan pertanyaan serta memberikan ide terkait cara dan jenis pohon yang sangat ideal untuk dijadikan pilihan dalam penanaman pohon. Terjadinya proses tanya jawab ini menandakan, jika peserta sangat memahami apa yang dijelaskan oleh para pemateri.

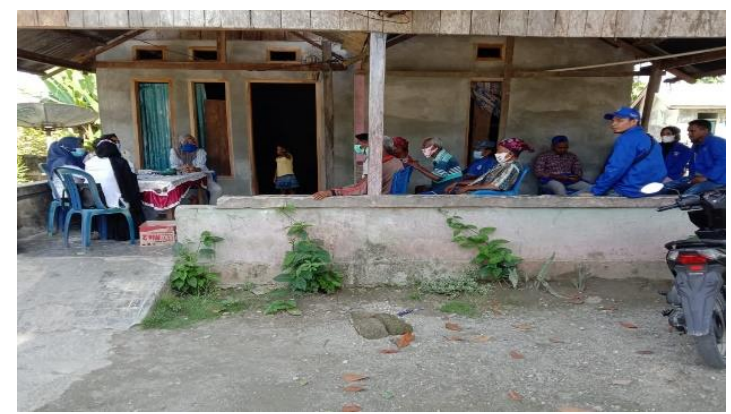

Gambar 1. Edukasi Penghijauan berbasis teori

\section{Edukasi Penghijauan Berbasis Praktik}

Edukasi penghijauan berbasis praktik dilaksanakan tim pengabdi dengan merangkul semua komponen masyarakat Dusun Waesuhan. Dalam penghiajuan ini, tim pengabdi menyediakan 100 bibit pohon untuk ditanam di beberapa titik lokasi yang telah ditentukan di Dusun Waesuhan.
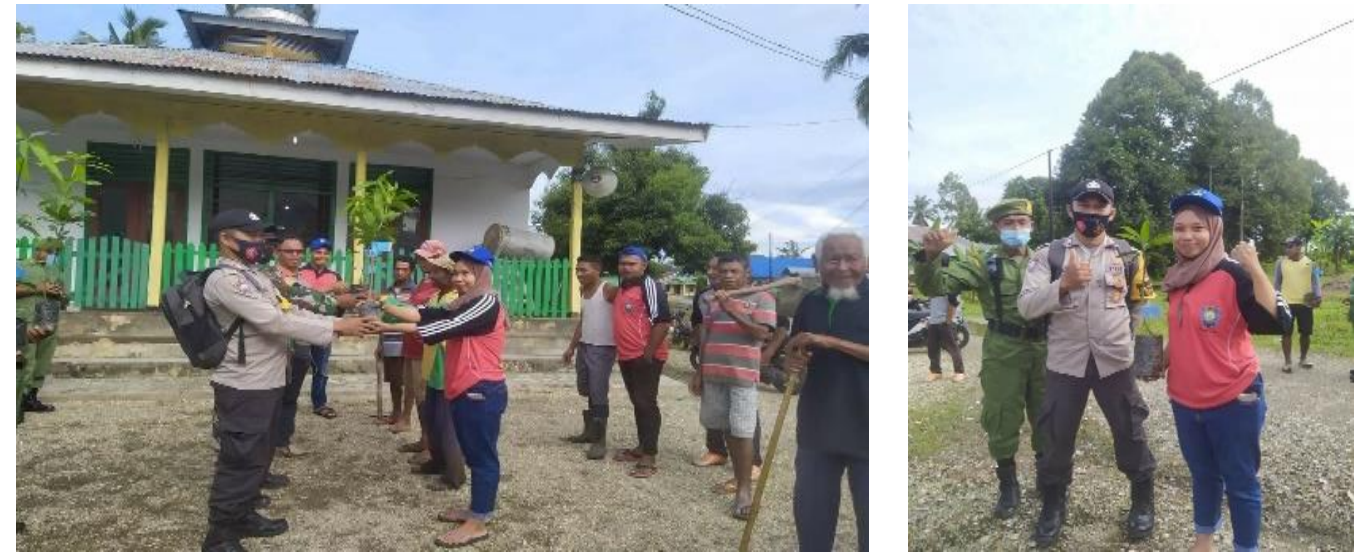

Gambar 2. Pelaksanaan Penanaman Pohon 


\section{Tahap Evaluasi}

Setelah kegiatan dalam program PKM (Pengabdian Kepada Masyarakat) tercapai, tim pengabdi akan tetap melakukan pendampingan dan pengontrolan di Dusun Waesuhan secara berkala. Tim pengabdi juga akan membandingkan hasil yang diperoleh oleh para masyarakat sebelum dan sesudah mendapatkan edukasi penghijauan ini. Selain itu, tim pengusul akan terus mengidentifikasi jika ditemukan masalah-masalah yang dihadapi oleh mitra sasaran.

\section{KESIMPULAN}

Berdasarkan hasil kegiatan yang diperoleh dari PKM ini maka dapat disimpulkan bahwa untuk menumbuhkan kepedulian masyarakat terhadap lingkungan salah satunya dengan pemberian edukasi penghijauan. Edukasi penghijauan dilakukan dengan dua cara, yakni edukasi berbasis teori dan berbasis praktik. Edukasi berbasis teori menekankan kepada dua materi inti, yaitu materi Pengelolaan Lingkungan Hidup dan materi Penghijauan. Sementara edukasi berbasis praktik, yakni dilakukannya penanaman pohon sebanyak 100 bibit pohon pada lokasi yang telah ditentukan. Hasil dari penerapan edukasi tersebut kepedulian masyarakat pada lingkungan semakin tinggi, hal tersebut ditandai dengan antusiasnya masyarakat Dusun Waesuhan mengikuti jalannya PKM ini. Selain itu, PKM ini juga berjalan dengan baik dan lancar, hal tersebut karena terciptanya kerja sama yang baik antara tim pengabdi dengan mitra sasaran.

\section{UCAPAN TERIMA KASIH}

Ucapan terima kasih disampaikan kepada Kerpala Desa Wanakarta yang telah memberikan izin terlaksananya PKM ini. Terima kasih pula kepada Ketua RT Dusun Waesuhan yang telah membantu hingga selesainya kegiatan PKM ini. Ucapan terima kasih tak terhingga kepada masyarakat Dusun Waesuhan atas partisipasinya.

\section{REFERENSI}

Adhistian, P., Mairizal, M., \& Dahniar, T. (2021). PENATAAN LINGKUNGAN DENGAN PENANAMAN POHON UNTUK MENCEGAH TERJADINYA LONGSOR DI DESA URUG, SUKAJAYA, BOGOR. Aphelion, 1(2), 169-176.

Harryanto, R., Sudirja, R., Saribun, D. S., \& Herdiansyah, G. (2017). GERAKAN PENGHIJAUAN DAS CITARUM HULU DI DESA CIKONENG KECAMATAN CILEUNYI KABUPATEN BANDUNG. Dharmakarya, 6(2), 78-82.

Imamah, N. (2021). GERAKAN PENGHIJAUAN SEBAGAI RINTISAN DESA WISATA UNTUK MENINGKATKAN INCOME MASYARAKAT DI DESA SUMOKALI, CANDI, SIDOARJO. Dinamis, 1(1), 26-33.

Pratiwi, D. A. (2017). PEMBERDAYAAN MASYARAKAT RW 12 DALAM KEGIATAN PENGHIJAUAN LINGKUNGAN DI KAVLING MANDIRI KELURAHAN SEI PELUNGGUT. Minda Baharu, 1(1), 25-32.

Setyobudiarso, H., Yuwono, E., \& Ma'ruf, A. (2020). KEGIATAN PENGHIJAUAN DI PESISIR WATU LATER DUSUN RAWATRATE, DESA SITIARJO, KABUPATEN MALANG. Solidaritas, 3(2), 48-53.

Wardani, N. R., \& Putra, D. F. (2020). PEMBERDAYAAN MASYARAKAT MELALUI PENGHIJAUAN UNTUK KONSERVASI SUMBER AIR BANYUNING KOTA BATU. Abdimas Berdaya, 3(1), 1-8. 